\title{
Epidemiología y Manifestaciones Clínicas de la Infección por SARS-CoV-2
}

\author{
Epidemiology and Clinical Manifestations of SARS-CoV-2 Infection
}

\author{
Luis A.Espinoza, MD
}

Resumen

En el último año la pandemia desatada por el COVID-19 ha afectado todos los territorios del mundo con más de 80 millones de casos y una mortalidad superior a 1.8 millones de personas. Al igual que otras recientes epidemias, esta epidemia de origen zoonótico parece haberse originado en los murciélagos aunque no se ha determinado el huésped intermedio. La mayoría de los casos, hasta en un $80 \%$, parecen tener síntomas menores pero hasta un $5 \%$ del resto pueden hacer enfermedad severa incluyendo falla respiratoria. El avance en el conocimiento de la enfermedad ha permitido que la mortalidad sea menor que al inicio de la pandemia y también en el desarrollo de algunas vacunas efectivas en un tiempo no visto antes en la historia de la medicina.

Palabras clave: Pandemia, COVID-19.

Abstract

Over the last year, the whole world has been affected by the COVID-19 pandemic, with over 80 million people affected with more than 1.8 million dead over the same period. Like other recent epidemics, this seems to be zoonotic in origin with the bats as the primary species harboring these coronaviruses but with a still unnamed intermediary host. Up to $80 \%$ of the cases have minor symptoms but $5 \%$ of the remainder may develop severe complications including respiratory failure. There has been a fast development of the knowledge about the disease in a very short period of time, making it a less lethal disease now as well as accelerating the development of several available vaccines.

Keywords: COVID-19, pandemia.

En diciembre del 2019 se reportaron en Wuhan, provincia de Hubei en China, los primeros casos de una neumonía de etiología desconocida ${ }^{(1)}$. En enero 7 de 2020, el CDC de China identificó a un nuevo coronavirus como el causante de esta enfermedad y unos días después se reportaron los primeros casos fuera de China, en Tailandia. Para fines del mes de enero del mismo año la Organización Mundial de la Salud (OMS) declaró el estado de emergencia mundial ${ }^{(2)}$. En febrero se anuncia el nombre del nuevo virus causante del síndrome respiratorio agudo como SARS-CoV-2 por sus siglas en inglés a la enfermedad como COVID-19. En la primera mitad de marzo se declara la pandemia y a finales de 2020 se habían reportado a nivel mundial más de 83 millones de personas infectadas y más de 1.8 millones fallecidos como consecuencia de esta pandemia. El país más afectado a esa fecha era Estados Unidos con alrededor de 20 millones de personas infectadas y más de 354,00 fallecidos. El Perú había reportado alrededor de 1 millón infectados y más de 37,000 fallecidos durante ese tiempo ${ }^{(3,4)}$.

\section{Origen del nuevo virus}

Los coronavirus han sido identificados en animales domésticos (pavos, vacas, cerdo, perros y gatos), además de ratones, desde la década de 1930 y recibieron ese nombre por la forma parecida a una corona. El primer coronavirus afectando humanos se describió en 1962, y desde esa fecha se han descrito siete diferentes coronavirus que afectan a los humanos, todos ellos teniendo un origen zoonótico en murciélagos, roedores o animales domésticos basados en secuencias de base de datos ${ }^{(5)}$.

${ }^{I}$ Past-President Peruvian American Medical Society (PAMS). Director Medico, Gilead Sciences Inc. 


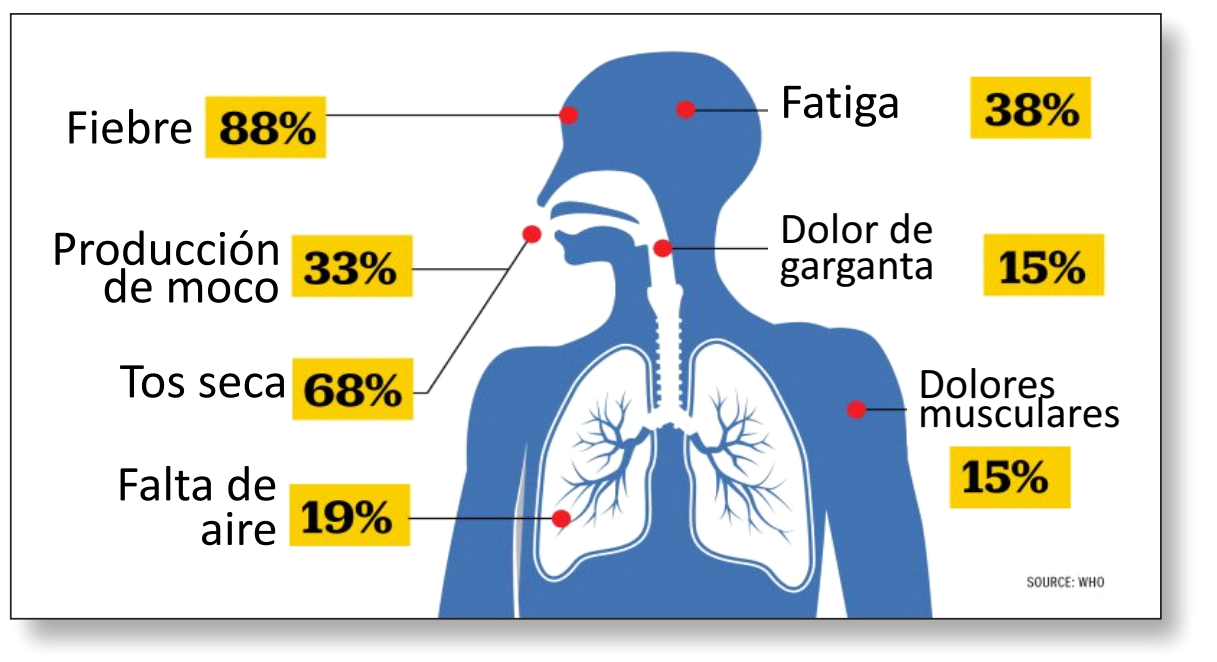

Figura 1. Síntomas más comunes del COVID-19.

Los últimos tres brotes de coronavirus (SARS-CoV-1, MERSCoV y SARS-CoV2) han ocasionado gran morbilidad y mortalidad. Se considera que los murciélagos son los huéspedes naturales para el SARS-CoV-2 pero hasta ahora no se ha podido señalar con exactitud cuál sería el huésped intermedio. Se ha considerado al pangolín como el más probable intermediario, aunque culebras y tortugas no pueden descartarse por el consumo de estos animales por humanos en su dieta o con fines medicinales ${ }^{(6)}$. (Figura 1 ).

Los murciélagos son un importante reservorio de virus zoonóticos que causan enfermedades en humanos y otros animales sin causar una enfermedad evidente en los murciélagos $^{(7,8)}$. La capacidad de los murciélagos de ser portadores de varios virus diferentes sin padecer enfermedad pareciera ser una respuesta de adaptación a su evolución. Aunque tienen una respuesta inmune robusta contra los virus ARN, ésta es disminuida contra los virus ADN probablemente debido al riesgo inmunopatológico de daño al ADN propio ${ }^{(8)}$.

Algunos virus, como el SARS-Co-V, pueden inhibir fuertemente la producción y actividad del interferón. En un estudio de pacientes muy enfermos con COVID-19 se observó un pico en la producción de interferón alfa-2 entre los 8 y 10 días después del inicio de síntomas. El peor desenlace y la mayor permanencia en las unidades de cuidados intensivos se dio en el grupo que tenía supresión de la producción de interferón ${ }^{(9)}$.

\section{Presentación de la enfermedad}

El tiempo medio de aparición de la enfermedad en el humano es de aproximadamente 5 días desde la exposición,

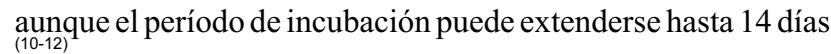

Se han reportado diferentes signos y síntomas como manifestaciones iniciales de la enfermedad y con variaciones en la intensidad de ellos. Las personas mayores de edad y con comorbilidades pueden manifestar una enfermedad más severa que las personas jóvenes o sin comorbilidades, e inclusive mayor riesgo de muerte ${ }^{(13)}$. Al igual que otras infecciones con otros coronavirus, las manifestaciones no se limitan al sistema respiratorio, pudiendo en algunos casos afectar múltiples órganos y llevar a una falla simultanea de varios de ellos e inclusive la muerte. Las manifestaciones más frecuentes incluyen: Fiebre y/o escalofríos, los cuales pueden no aparecer inicialmente, pero manifestarse cuando la enfermedad progresa; tos con dificultad para respirar o falta de aire, y dolor de garganta. Muchos pacientes se quejan de cefalea, pérdida del gusto (disgeusia) y del olfato (anosmia), además de congestión nasạl; también se han reportado síntomas gastrointestinales como nausea, vómito y diarrea ${ }^{(14)}$. (Figura 2 ). Se ha reportado que la disgeusia y anosmia pueden ser síntomas únicos de la presencia de la infección. También se ha reportado persistencia de anosmia y disgeusia aun después de superada la infección por coronavirus $^{(15)}$. Algunas personas que se han recuperado del COVID-19 tienen algunos síntomas persistentes por tiempo prolongado tal vez debido a que, similar a otros coronavirus, el SARS-CoV-2 puede permanecer en el organismo desencadenando respuestas inmunes aún sin replicarse. El compromiso serio de varios órganos o sistemas de pacientes se desarrolla a más detalle en otras presentaciones del Simposio (Parte 1 y 2), como el compromiso cardíaco, pulmonar, renal y del sistema de coagulación. 


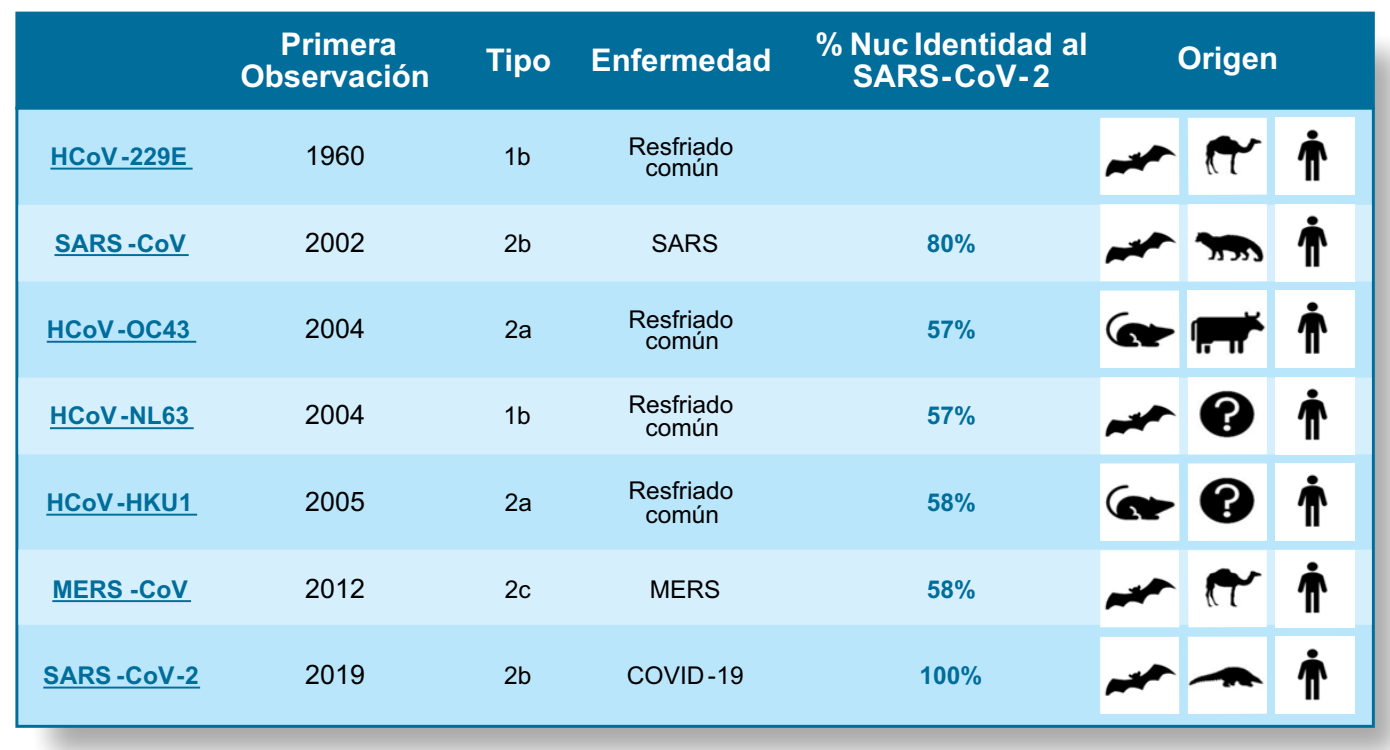

Figura 2. Coronavirus que afectan a los humanos, orígen y probable huésped intermedio.

Se han descrito pacientes que fueron diagnosticados con pruebas moleculares pero que no presentaron ningún síntoma. El mecanismo por el que esto ocurre no es totalmente claro. Esto implicaría que el número de personas infectadas es mayor al que actualmente se ha reportado y tiene repercusión en lảs medidas a adoptar para el control de transmisión de la enfermedad $^{(11,12)}$. Si bien la letalidad del SARS-CoV-2 es menor comparado a los otros coronavirus como SARS y MERS, la transmisión es mucho más fácil y facilita la diseminación ya que las personas asintomáticas o con síntomas mínimos pueden no darse cuenta de estar infectados ${ }^{(16)}$.

Nos encontramos ahora en medio de la pandemia ocasionada por el SARS-CoV-2 y desconocemos la duración de la protección que tendrá la inmunidad al virus. Las reinfecciones con los cuatro coronavirus que causan el resfriado común ocurren en un promedio de 12 meses. En estudios con los genéticamente similares beta-coronavirus SARS-CoV-1 y MERS, los anticuerpos persisten por aproximadamente dos años, aunque se desconoce si esto produce protección contra la infección ${ }^{(17)}$. Aunque en números pequeños comparados al tamaño de la pandemia, se han documentado casos de reinfección con SARS-CoV-2 en diferentes lugares del mundo. Los casos reportados parecen ser de menor intensidad que el cuadro inicial debido a que de todas maneras parece haber cierto grado de inmunidad con la primera infección. Las personas que tienen una infección inicial leve parecen perder los anticuerpos más tempranamente (posiblemente en algunos meses) aunque los anticuerpos neutralizantes, al igual que las células T y B de memoria, parecen persistir por lo menos durante seis meses. Esto tendrá implicaciones en los programas que se implementen para controlar la epidemia.

Es muy difícil que se logre la inmunidad de rebaño a mediano plazo como un modo de control de la pandemia y las otras medidas de prevención, como el uso de máscaras y mantenimiento de la distancia social, se deberían mantener hasta completar los programas de vacunación ${ }^{(18)}$.
Referencias bibliográficas

1. Huang C, Wang Y, Li X, et al. Clinical features of patients infected with 2019 novel coronavirus in Wuhan, China. Lancet. 2020;395:497-506. doi:10.1016/S0140-6736(20)30183-5

2.h t t p s : / / w w w w ho. in t / o c s / d e f a u l t source/coronaviruse/who-china-joint-mission-on-covid-19final-report.pdf

3. https://www.worldometers.info/coronavirus

4. https://coronavirus.jhu.edu/map.html

5. Ye ZW, Yuan S, Yuen KS, Fung SY, Chan CP, Jin DY. Zoonotic origins of human coronaviruses. Int $\mathrm{J}$ Biol Sci.
2020;16(10):1686-1697. Published 2020 Mar 15. doi:10.7150/ ijbs. 45472

6. Zhao J, Cui W, Tian BP. The Potential Intermediate Hosts for SARS-CoV-2. Front Microbiol. 2020;11:580137. Published 2020 Sep 30. doi:10.3389/fmicb.2020.580137

7. Schountz T. Immunology of bats and their viruses: challenges and opportunities. Viruses. (2014) 6:4880-901. doi: $10.3390 / \mathrm{v} 6124880$

8. Banerjee A, Baker ML, Kulcsar K, Misra V, Plowright R and Mossman K. (2020) Novel Insights Into Immune Systems of 
Bats. Front. Immunol. 11:26. doi: 10.3389/fimmu.2020. 00026

9. Fung SY, Yuen KS, Ye ZW, Chan CP, Jin DY. A tug-of-war between severe acute respiratory syndrome coronavirus 2 and host antiviral defense: lessons from other pathogenic viruses. Emerg Microbes Infect. 2020;9(1):558-570.Mar 14 doi:10.1080/22221751.2020.1736644

10. Guan WJ, Ni ZY, Hu Y, et al. Clinical Characteristics of Coronavirus Disease 2019 in China. N Engl J Med. 2020 Apr 30;382:1708-doi:10.1056/NEJMoa2002032

11. Li Q, Guan X, Wu P, et al. Early Transmission Dynamics in Wuhan, China, of Novel Coronavirus-Infected Pneumonia. N Engl J Med. 2020 Mar 26;382:1199-207. doi:10.1056/ nejmoa2001316

12. Lauer SA, Grantz KH, Bi Q, et al. The Incubation Period of Coronavirus Disease 2019 (COVID-19) From Publicly Reported Confirmed Cases: Estimation and Application. Ann Intern Med. 2020 May 5;172(9):577-82. doi:10.7326/M200504

13. Zhou F, Yu T, Du R, Fan G, Liu Y, Liu Z, Xiang J, Wang Y,
Song B, Gu X, Guan L, Wei Y, Li H, Wu X, Xu J, Tu S, Zhang Y, Chen H, Cao B. Clinical course and risk factors for mortality of adult inpatients with COVID-19 in Wuhan, China: A retrospective cohort study. Lancet 2020;395:1054-1062.

14. https://www.cdc.gov/coronavirus/2019-ncov/hcp/clinicalguidance-management-patients.html

15. Wang Y, Liu Y, Liu L, Wang X, Luo N, Ling L. Clinical outcome of 55 asymptomatic cases at the time of hospital admission infected with SARS-Coronavirus-2 in Shenzhen, China. J Infect Dis. 2020 Jun 1. doi:10.1093/infdis/jiaa119

16. Bai Y, Yao L, Wei T, et al. Presumed Asymptomatic Carrier Transmission of COVID-19. JAMA. $2020 \mathrm{Feb}$ 21;323(14):1406-1407. doi:10.1001/jama.2020.2565

17. Anderson DE, Tan CW, Chia WN, et al. Lack of crossneutralization by SARS patient sera towards SARS-CoV-2. Emerg Microbes Infect, 2020;9(1):900-902.

18. Jeffrey I Cohen, Peter D Burbelo. Reinfection with SARSCoV-2: Implications for Vaccines, Clinical Infectious Diseases, ciaa1866, https://doi.org/10.1093/cid/ciaa1866

Contribución de autoría: Luis A. Espinoza ha sido el autor del estudio, contribuyendo con su concepción,

búsqueda electrónica, revisión inicial, el diseño de estudio, redacción, y revisión final.

Conflicto de interés: El autor no tiene conflictos de interés con la publicación de este trabajo.

Financiamiento: Autofinanciado.

Citar como: Espinoza LA. Epidemiología y Manifestaciones Clínicas de la Infección por SARS-CoV-2.

Diagnóstico(Lima). 2020;59(4):194-197.

DOI: 10.33734/diagnostico.v59i4.255

Correspondencia: Luis A. Espinoza. Correo electrónico: espinozalui@gmail.com

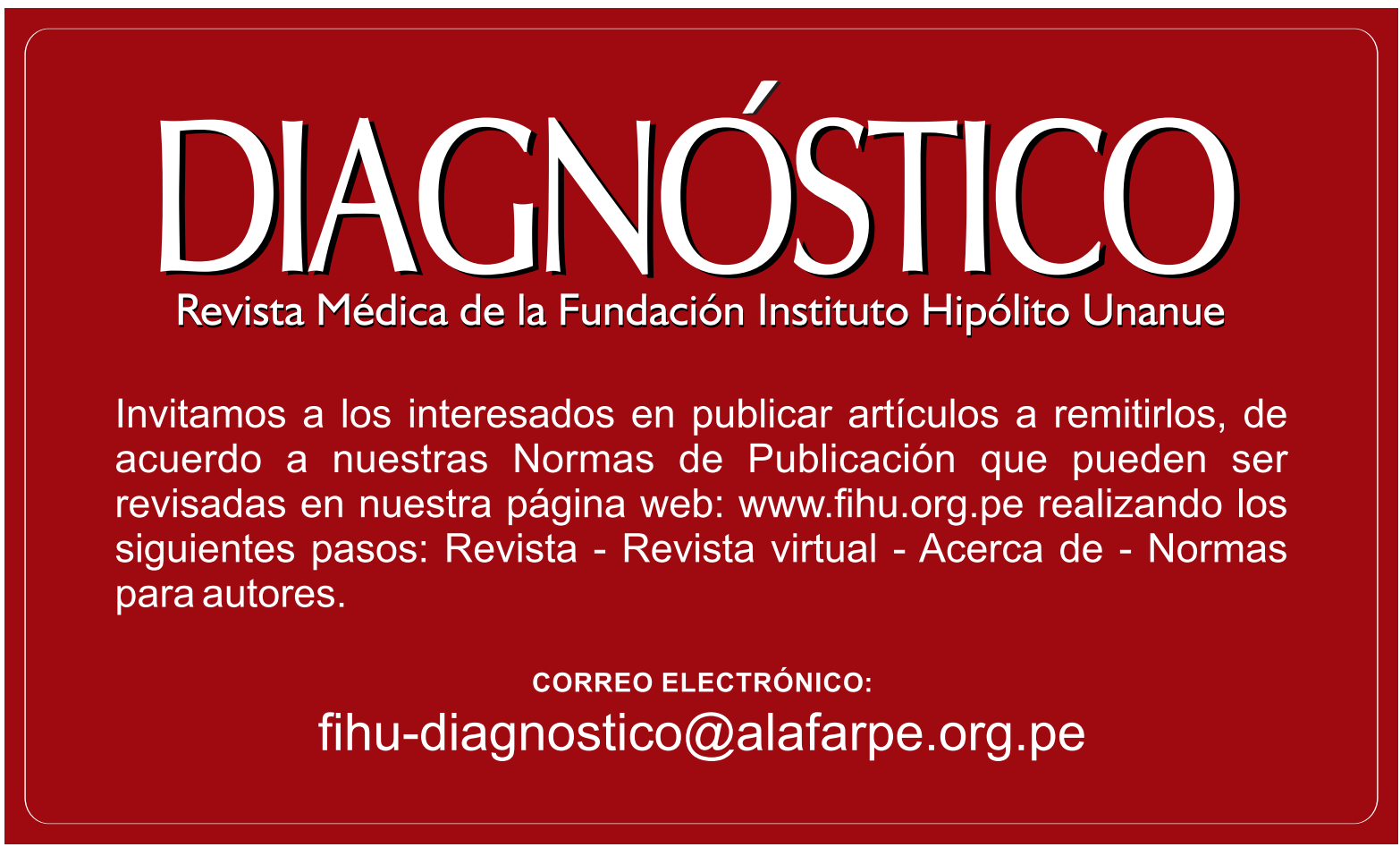

